\title{
The Two Futures of Governing: Decentering and Recentering Processes in Governing
}

B. Guy Peters ${ }^{1}$

\begin{abstract}
Reforms of the public sector have helped create a more efficient and effective public sector, but they have also created a number of problems. Both the New Public Management and "governance" reforms have contributed to the contemporary problems in governing. These problems have been political to a great extent, reflecting the tendency to emphasize administrative rather than democratic values. Governments have begun to react to the real and perceived problems within the public sector by developing a number of "meat-governance" instruments that can help steer public organizations but which involve less direct command and control. This paper addresses the contemporary governance tasks of restoring political direction and policy coherence while at the same time supporting the autonomy of public organizations, and the involvement of policy networks, in governing.
\end{abstract}

\section{The Two Futures of Governing: Decentering and Recentering Processes in Governing}

The public sector in most of our countries has undergone significant change during the past several decades. Whether the changes have been described as "reform", "modernization", "reinvention" or whatever, most governments now are vastly different from what they were even a few years ago. These changes have, in general, produced governments that are more efficient and effective. Further, although most of the reforms implemented have been conceived largely within the market model (Peters 2001), public administration is now also more open to public participation in many countries and also has been opened to greater participation by lower echelon public employees.

1 Department of Political Science, University of Pittsburgh. 
The dominant pattern of reform of the public sector over the past several decades has been discussed as the "New Public Management" (Hood 1991; Christensen and Laegreid 2001), or simply NPM. The basic idea of NPM has been that government should be made to be more efficient and effective, and that the best way of achieving these goals is to make the public sector perform more like the private sector. One component of these reforms has been to enhance the autonomy of managers and their organizations, with the assumption that if managerial talent were unfettered by internal rules then the public sector would be more efficient (Dilulio 1994). In addition, this autonomy was to be enhanced by creating numerous autonomous organizations (see Niskanen 1971) such as the "Next Steps Agencies" in the United Kingdom.

Although the participatory dimension of change may have been discussed sotto voce in many reform processes, it has become a more central conception of reform. In particular, while many of the initial stages of reform were discussed as the New Public Management ${ }^{2}$, the increased interest in "governance" styles of reform has enhanced the participatory dimension of change (Peters 2005). Like the idea of the New Public Management, "governance" as a concept can be extremely vague (see Pierre and Peters 2000), and has been the subject of significant academic contestation. That having been said, most of the "governance-style reforms" implemented by governments have emphasized the role of social actors in making and implementing policy and especially emphasized the role of networks and analogous structures in the processes of governing societies.

While both the New Public Management and governance styles of reform have made significant contributions to the performance of the public sector, they have also created a number of significant problems within government. In particular, both styles of reform have tended to create problems of incoherence and poor coordination in the public sector (see Bakvis and Juillet 2004), and, in addition, those reforms have created extensive accountability problems (Mulgan 2000). Therefore, like almost every other reform initiative before them, both NPM and governance reforms have engendered a host of new reforms, and the process of attempting to "make government work better and cost less" continues unabated. ${ }^{3}$ Very much like Herbert Simon famously argued approximately 60 years ago, most of the adages used in public management (and indeed private management) have opposites that are equally valid in the right circumstances.

Given the above discussion, we are dealing with several alternative futures for the public sector in most industrialized democracies. Both of these futures will

2 This term was, and is, extremely broad and to some extent included participatory ideas as well as the market-based efficiency concepts. See Hood (1991).

3 This phrase was, of course, the sub-title of the National Performance Review (Gore Commission) in the United States but came to represent a general ambition for reformers in the public sector. 
involve change, and both will require continuing investment of political capital in order to be effective. Further, the central feature of these two futures is that one need not make a definitive choice between them. Both are feasible, and their effects will be complementary. The central political question is not so much one of making a choice between the two, but rather finding a way of making the two fit together in an effective, and democratic, manner.

\section{One Future - Continuing the Current Patterns of Reform}

Although I have been discussing them as alternative models of the public sector, as indeed they are, the patterns of reform that have shaped contemporary government have a number of things in common. Phrased in the most general manner, these reforms have tended to move the process of governing out of the center of government. These reforms have involved a number of different changes in patterns of governing, including:

1) Deconcentration. One of the most important changes associated with the New Public Management has been creating a number of new autonomous or quasi-autonomous organizations - often referred to as agencies (Pollitt and Talbot 2004; Verhoest, Rubecksen and Humphreys, forthcoming). A good deal of policy-making and implementation in contemporary political systems has been delegated to these organizations, under the assumption that single-purpose organizations with managerial autonomy will allow skilled public managers to improve the quality of public services. This deconcentration also represents some denigration of politics and politicians in the process of governance.

2) Decentralization. As well as moving some of the functions of the public sector out to devolved organizations within central government, another strategy has been to decentralize activities and give greater responsibility to sub-national governments. The logic of decentralization is in part to improve efficiency, given an assumption that smaller units will provide services better. Also, decentralization can be justified on democratic grounds, with the public having perhaps greater opportunity for involvement at lower levels of governing.

3) Delegation. A final strategy for reforming the State has been to delegate public authority to a variety of other actors (for general models see Huber and Shipan 2002). In the market approach to governing, much of that delegation has been to contractors and to other market actors. In the governance model, much of the delegation would be to networks and to not-for-profit organizations. Both types of delegation can be thought to improve the efficiency of the public sector, and the use of networks of social actors also generally is argued to be important for enhancing the democratic element of governing. 
We might be able to add to this list of descriptions of change, but taken together, all the reforms mentioned here involve "decentering" the governing process (see also Peters 2004). Although obviously different in terms of their details, and in terms of their justifications, the impact of all of the changes in the public sector has been to minimize control from the center of government - presidents, prime ministers and even individual ministers. ${ }^{4}$ Thus, they all have at their heart an assumption (explicit or implicit) that government will work better if the political center is devalued and if public administrators and private sector actors are more responsible for delivering services.

\section{From Reform to New Problems Created by Reform}

The above changes in the public are often justified by the familiar "steering not rowing" logic (Osborne and Gaebler 1991), assuming that governments are better at setting directions for policy than they are at actually delivering those policies. In reality, however, these reforms may also have reduced the steering capacity of the public sector, and in particular have reduced the capacity that political officials have enjoyed in the past for exercising control over the policies of their governments. This reduction of the "primacy of politics", has in turn created several governance problems:

1) Politics and Steering. As already implied, the emphasis on moving activities away from the center of government has reduced the capacity of elected officials to exercise control over these policies, even though in democratic politics, we assume that elections are about choosing policy (see Rose 1974; Caplan 2007). To the extent that so much of government activity is delegated, then political leaders are left with few levers, and often poor-quality levers, with which to affect the course of their own governments. Any number of prime ministers have expressed their feelings of impotence in the context of contemporary patterns of governing, but significantly fewer have actually done anything about attempting to redress that balance (but see below).

2) Coordination. A second difficulty resulting from the decentering of the public sector have been reduced levels of coordination among policies and organizations. The notion of first splitting up large organizations into a number of small organizations, and then giving organizations greater autonomy has been central

4 This argument appears to be in direct contradiction to that usually found in comparative politics which emphasizes the decline of parliamentary and even cabinet government in favor of prime ministerial domination - often incorrectly called the presidentialization of parliamentary regimes (see Von Mettenheim 1997; Heffernan 2003). That argument, however, focuses more on the political control of the process within government and changes in media focus rather than on the actual capacity of political executives at the center of government to control service provision by their own governments.

5 This term has come to be commonly used. For one of the earlier uses see Pollock (1951). 
to reforming, especially the creation of agencies. The numerous organizations operating with increased has, however, tended to exacerbate the familiar problems of coordination and coherence in the public sector. The proliferation of organizations, in turn, also contributes to the difficulties in exercising political control.

3) Complexity. The larger number of organizations involved in governing, and the multiple ways in which they are linked to the more conventional parts of the public sector, also increase the complexity of governing. While complexity is not per se detrimental, it may counteract some of the efficiency gains generated through management changes. That is, the increased number of veto points in the system, and the difficulty in gaining acceptance at all those points does reduce chances of success. Further, complexity does tend to reduce the transparency of the public system and therefore affects accountability (see below).

4) Capture. By separating public organizations from direct connections to political authority, the decentering reforms tend to make those organizations more vulnerable to capture by other interests. This is a classic problem in the analysis of independent regulatory agencies in the United States and elsewhere, but the logic can be extended to cover a range of other organizations that have been detached from political support. The capture may be by local geographical interests (Whitford 2002) or by functional interests, but the idea of depoliticizing government tends to lead to other forms of politicization, often of a less desirable sort.

5) Accountability. Finally, and perhaps most importantly, the reforms in the public sector have generated major accountability problems. One virtue of the "primacy of politics" is that it identifies clearly a hierarchy of accountability in the public sector and also identifies a number of mechanisms for enforcing that accountability. When there are a number of alternative relationships between elected politicians and service provision, and many of the service providers assume that they are meant to act autonomously, then identifying responsibility for actions is difficult.

Thus, both from the perspective of democratic theory and from the perspective of policy capacity, the reforms associated with the New Public Management approach, as well as those coming from the governance approach, have generated a substantial need for further change. As I will point out below, these changes can not be a simple return to the status quo ante with public sector dominance, although some scholars are arguing for a return to more traditional forms of public management (Olsen, forthcoming). Too much change has occurred, and governments have learned too much about alternative mechanisms for delivering services to be able to make a simple return to the bureaucratized, hierarchical model of governing (see Walsh and Stewart 1992). In part, the changes in the public sector associated with 
these two reform movements have created substantial improvement in the functioning of the public sector, at least at the levels that are more micro. ${ }^{6}$

That having been said, however, the movement away from that style of governing has to some extent been exaggerated, and much of the old system remained in place, if subsumed under the facade of new forms of governing (Schofield 2001). Further, some scholars are also discussing the return to a Weberian style of governing in many settings, with a perceived need to reinvigorate some of the mechanisms for control and probity that were components of more traditional forms of governing. This is far from just being reactionary, but represents the need to recreate some values that were central to making governments both effective and accountable, and which have not been replaced adequately by the products of reform.

Leaving aside the return to a more Weberian style of governing, most of the problems generated by the NPM and "governance" reforms can be encapsulated in the problem of democratic government. Again, if elections are about selecting policy as well as leaders, and if those leaders once elected find that they have less influence over policy than they, and probably their voters, believe is appropriate, then there is a fundamental democratic problem. Even if the elected leaders are able to do some of their steering without the rowing, their level of policy control may not be as great as desired. This loss of control is true for policy choices, but is even more true given the crucial role that implementation plays in determining the true meaning of policy (Meyers and Vorsanger 2004).

\section{The Center Strikes Back}

Having recognized their own difficulties in exercising control over the public sector, a number of governments have begun to take action to attempt to restore control over the public sector. In some instances, this shift in ideas about governing has reflected particular political circumstances, including changes in the political parties controlling the public sector. In other cases, the attempt to reimpose greater political control has reflected more fundamental changes in ideas about governing. These changes reacting to the problems created by NPM et al. have not had the generality of either NPM or governance ideas, but they do reflect the perceived need to recapture some of the political steering that has been lost.

Some of the attempts to reimpose control over governing have tended to run counter to many of the canons of "good governance". In particular, when faced with the a number of organizations and programs over which they perceive themselves to have little direct control, political leaders have tended to politicize the management

6 By that I mean that the closer one gets to the actual delivery of services, and especially to the operations of individual organizations, the greater the benefits of reform have been. When more systemic factors in governing are considered, the benefits of the reforms may be negligible, or indeed the costs may outweigh any benefits. 
of those programs. A number of studies of the public sector in the industrialized democracies (Peters and Pierre 2004) have shown that political leaders have found themselves in the position of having to take political responsibility for programs that they have little capacity to influence directly, and that this is an extremely uncomfortable position for those leaders. One of the simplest means of attempting to gain such control is to have one's own people managing the programs, e.g. to move toward higher levels of political appointment. Somewhat paradoxically, the internal deregulation of public employment fostered by NPM has facilitated those appointments. ${ }^{7}$

In addition to politicization, the decentering of the State has tended to engender the identification of scapegoats and denial of responsibility. As noted, political leaders may believe that they are being held responsible without justification, and in turn attempt to shed that responsibility. To some extent the complaint is justified, given that many of the linkages associated with effective responsibility and accountability have been weakened, and many of the levers for control have been eliminated. In fact, even some of the mechanisms being used in an apparent attempt to create responsibility for service provision may, in the end, dilute that responsibility. For example, the increasing use of "czars" for problem areas of public service tend to deflect attention, and potentially accountability, away from the political leaders and in the direction of the "czar".

Not all of the reactions to the perceived loss of political control have been as negative as those already discussed. Perhaps most obviously, a number of governments have been attempting to build mechanisms for coordinating the numerous programs and autonomous organizations that have been created. One of the more obvious of these attempts has been the movement of "joined up government" in the United Kingdom, but there have been analogous programs in a number of other countries (Pollitt 2005; Christensen and Laegreid 2007; Gregory 2004). The basic idea has been to attempt to integrate government after it had been disaggregated by previous regimes. In some cases, the attempt was structural, but in others, there was a more intellectual thrust of attempting to create more "holistic" government that could provide a relatively seamless web of services (6, Leat, Setzler and Stoker 2004).

7 It is quite possible that these appointments are perfectly qualified as managers, but it is very clear that there are more political forms of appointment, and that those appointments give the appearance of politicizing the public sector in ways that have been unacceptable in many political systems.

8 The Blair government in the United Kingdom was the most enthusiastic user of czars for problems such as the railways, several aspects of the National Health Service, and for children's services, among others. This mechanism enables the Prime Minister or a minister to argue that something has been done and thereby to (attempt to) escape personal political accountability for the outcomes. 
To some extent the notion of joining up government, while certainly a valuable contribution to governing, missed some of the crucial elements of the decentering reforms. The attempts to improve coordination were indeed joined up government and apparently, they were less interested in joining up the other non-governmental aspects of governing that had become so important. In fairness, attempting to produce integration at that level would be more difficult, and might even be counterproductive, if viewed from rather conventional perspectives of governing. That is, simply attempting to bring the various relationships with social actors into a single format, and/or to reduce autonomy, may eliminate the gains from the previous reforms without necessarily creating commensurate benefits.

\section{The Gap}

The discussion to this point reveals the presence of two distinct formats for contemporary governance. As already noted, these two styles, while distinct, are also to a great extent complementary. One governance style emphasizes the need to improve the quality of service delivery, the management of individual organizations and the democratization of those services. The reforms associated with both NPM and with "governance" have been successful in a number of cases, but then created the need for the second pattern of change, one that emphasizes the need to coordinate, create greater coherence and to restore the primacy of politics. Each of these approaches to governing constitutes an important contribution to the capacity to provide better governing, but they are rather different. The major task in governing, therefore, may become to "knit" together the two alternatives.

In addition to the practical issues of governing involved, these two approaches to governing represent interesting theoretical concerns. On the one hand, there have been important theoretical developments in the area of "governance" (Sørenson and Torfing 2000; Klijn and Koopenjan 2005). As implied above, this term has come to mean a number of different things, but perhaps the dominant strand has emphasized the need to consider the process of providing direction to society, and providing public services, as involving actors well beyond those nominally in the public sector. Thus, the "governance" reforms mentioned above address the involvement of a wide range of actors in making and delivering services, and that involvement is reflected as justified in a growing body of social scientific literature.

One could argue that the concern with governance is old wine in new bottles given that, especially in Northern European countries, varieties of corporatism and corporate pluralism (Rokkan 1967) have been in existence for decades, if not centuries. The reality of the involvement of social actors with the public sector has to some extent changed as networks have strengthened. Further, the theory surrounding that involvement of private sector actors has certainly changed. For example, rather than much of the involvement being motivated by the State itself (even in the 
corporate pluralist model), contemporary modes of "governance" allow for greater autonomy exercised by the social actors, and more autonomous self-organization of the networks that are to provide governance. ${ }^{9}$

While governance theory, and its development of the logic of networks, has made a number of contributions to our understanding of the processes of steering the economy and society, it also has a number of internal problems. One of the most important of these problems has been the assumption of decision-making capacity of networks. The network model appears well-suited for conditions in which the principal actors agree on goals and on means, but paradoxically if there were that level of agreement then there might be no need for the networks in the first instance. ${ }^{10}$ While the networks are advanced as alternatives to conventional forms of governing, they lack pre-determined decision rules that both enable decisions to be made in the most difficult of circumstances and also legitimate those decisions. ${ }^{11}$

In addition to the problem in making decisions at all, the absence of clear decision rules may lead to the decisions that possible being sub-optimal. Much as Fritz Scharpf (1988) argued about decision-making in multi-level governance systems, the need to reach consensus may lead to decisions by the lowest common denominator. If there are multiple constituencies with potentially extremely different ideas about policy, then the only way to resolve the conflicts may be to find the few points of agreement. The more or less incremental outcomes from that type of decisionmaking process may please established interests within the networks, but may add little to the capacity for innovation and for major policy change (but see Dente, Bobbio and Spada 2003). That having been said, assuming that such incremental decisions could be made, implementation would be facilitated because the potential opposition to change would be coopted into the decision.

Finally, and most importantly perhaps, the delegation of substantial amounts of authority have led to major problems of democracy. These democratic problems involve not only accountability but also representation - both fundamental democratic values. This is, of course, rather paradoxical given that one of the principal justifications for at least some aspects of delegation has been to enhance public involvement. Despite those good intentions only members of certain groups may be

9 That being said, some scholars of governance do note the extent to which the State is crucial for establishing the framework under which the involvement of those actors are granted powers to make and implement policy. Likewise, networks might have little raison d'être, were State authority, even if delegated, available for the implementation of the decisions made. These factors are crucial for the meta-governance arguments presented below.

10 The most obvious case would be epistemic communities in which there is an agreement based on a common professional or scientific body of knowledge (see Adler 1992).

11 Majority rule in legislatures, for example, permits decisions to be made even in the face of conflict, while the more consensual logic of networks may make such decision-making difficult. Further, as these constitutional decision rules are known in advance, they tend to legitimate those decisions, at least in the procedural sense of the term (Buchanan and Tullock 1962). 
involved in the networks, and especially "potential groups" with low levels of organization may not be represented adequately.

These challenges to governance theory mirror very closely the problems faced by governments in the "real world" discussed above. Delegation to networks, contractors, sub-national governments or whatever other actor may be used to make and implement policy creates agency problems, so that the political principals can not produce effective control (Huber and Shipan 2002). Whether the problem is phrased in terms of principals and agents, or in terms of more overtly political control issues, critics of governance have questioned the capacity of these models to explain adequately the actual selection and delivery of services, especially when considered in a democratic framework.

\section{Bridging the Gap: Meta-Governance}

The theoretical development in governance has now extended to the idea of "metagovernance", meaning in essence the governance of governance (see O'Toole 2007). The weaknesses of governance as an encompassing concept for describing what occurs within the contemporary processes of governing have become more apparent, even to some advocates of the approach. This awareness has generated the need to think about the means of building into governing processes increased control, while at the same time permitting some autonomy for the networks and other forms of decentered governing. Any reasonable conceptualization of contemporary governance processes must contain a great deal of decentered activity and recognize that it is impossible to return to the status quo ante. At the same time, however, that conceptualization must also recognize that all of the requisite functions of governing a society can not be fulfilled by those decentered processes. ${ }^{12}$

Developing a working conception of meta-governance therefore helps to bridge the gap between the disaggregated processes within the contemporary public sector and the desire of many political principals to restore some direct control. In the most blunt terms then, meta-governance would simply be reneging on the delegations of power and recentralizing controls in the structures associated with the "conventional" public sector. As already argued, such a simplistic response is unlikely to be successful and may not be politically viable. ${ }^{13}$ The reforms of the past several decades are not unpopular with many people in and out of government and have created their own constituencies. Further, the ideology of New Public Manage-

12 Yes, this is a functionalist approach to politics and government. Although often denigrated, functionalist approaches do have the capacity to identify important issues and also to identify the possible solutions to those problems. In particular, in this instance, knowing what must be done to govern helps to understand why the decentered formats may be inadequate.

13 The politics involved here are more likely institutional politics, defending the prerogatives of some organization or program or other, rather than partisan politics. Those institutional interests may, of course, be connected to the social interests being served by the organizations involved. 
ment continues to be widely accepted, and those ideas continue to motivate policy choices concerning internal management. The discourse surrounding public management has been altered in a fundamental manner so that any simplistic atavistic response is unlikely to be acceptable.

As well as thinking about meta-governance as a simple reaction to changes in the public sector and an attempt to recreate the past, it must also be understood as creating the conditions under which governance models can perform effectively. For example, much of the governance literature assumes that networks are self-organizing and autonomous, but in many cases, they must be created and fostered, often by the State. Likewise, in order to be effective, a network must have a point of access in the public sector that legitimates and motivates the involvement of the members, with public bureaucracies providing most of those points of access. In addition, the actions of any policy network may have to be legitimated, and the formal institutions of the public sector themselves may be crucial for that legitimation. In short, no matter how substantial the internal capacity of the network may be, it may not be effective without the active involvement of government.

\section{The Instruments of Meta-Governance}

Governments have at their disposal much of the same toolbox for meta-governance that they have for coping with other policy problems, but those tools are available in somewhat different mixtures. The mixture has changed in part because of the specific tasks, that of meta-governance as opposed to attempting to influence society. Importantly, meta-governance involves attempting to shape behaviors of organizations that have some political legitimacy of their own so that some of the usual authoritative relationship may not be as viable. The mixture of tools is now also different for meta-governance because there has been some general move toward "New Governance" (Salamon 2001), implying using negotiation, bargaining and broader ranges of compliance than in conventional command and control styles of intervention. Given the general differences in meta-governance from governance, it is necessary to consider some range of alternatives, or complements, to those conventional mechanisms.

\section{Priority Setting}

Perhaps the fundamental strategy for meta-governance is establishing priorities, and establishing them politically. A fundamental weakness in the network and other decentered forms of governing is that all programs and goals are virtually equal. This equality is largely a function of delegating authority to organizations, all of whom presume that their programs are at least as valuable as everyone else's program. Likewise, even if the decentered aspects of government are autonomous and quasi-autonomous organizations, they still assume that they have been granted that 
autonomy in order to pursue their own goals, rather than any more comprehensive goals for the "Whole of Government". ${ }^{14}$

Priority setting can be accomplished in a variety of ways. Most involve enhancing the capacity of presidents, prime ministers and their central agencies. This need to strengthen the center may appear somewhat ironic, given the tendency of parliamentary regimes to discuss the "presidentialization" of politics, but the focus on the chief executive is often more a media event than a reflection of the capacity for governance (Peters 2007). There are some real attempts to strengthen the center and establish priorities. For example, the Finnish government now creates several cross-cutting programs as components of the coalition documents for each new government (Bouckaert, Ormond and Peters 2000). Other governments have attempted to restore some capacity to govern from the center (Savoie 2004), but the capacity to govern from the center still appears weaker than might be expected.

\section{Soft Law}

If conventional uses of authority are not appropriate for the tasks of meta-governance then some "softer" alternatives may the be necessary response. The shift to soft law has been evident not just for meta-governance but like other elements of new governance has been applied to a range of situations (Morth 2003). The basic notion of this approach to governing has been to use instruments such as benchmarks, guidelines, frameworks and a host of other mechanisms that establish ranges of compliance rather than specific points of compliance. Further, these instruments tend to be the products of discussions and negotiations rather than imposition from above.

The nature of soft law is to establish ranges of compliance and provide direction rather than command action. This response to the meta-governance problem reflects the need to steer but continue to do so at a distance, allowing a range of responses from networks or local governments. The "softness" of the law may vary depending upon the object of the steering. For example, attempting to control subnational governments that have some political base of their own may be more challenging than attempting to control the private members of a network. Further, the capacity to use soft law effectively may vary across policy areas, with those involving more directly the formal powers of the State being less amenable to informal styles of steering and governance. ${ }^{15}$

14 This term has been used by the Australian government and several other national governments to indicate the importance of creating more comprehensive approaches to governing. Even in those cases, however, the links to private sector organizations, and even sub-national governments, delivering public services often are not adequately institutionalized.

15 For example, see the discussion of informal governance mechanisms by Helmke and Levitsky (2004). 


\section{Maintaining The Golden Thread}

Strategies of decentering government and loosening control involve minimizing direct controls over organizations and networks. For actors at the center, however, reducing levels of control may not mean totally abandoning it, and some means of control may still be maintained while simultaneously permitting autonomy in other areas of activity. Indeed, one of the more interesting aspects of the contemporary discussions about autonomy and control within the public sector is the dance being danced by central control structures and agencies, quangos and sub-national governments to whom substantial autonomy has been granted, at least in theory (see Yesilkagit 2007).

Analytically, we (Bouckaert, Peters and Verhoest 2007) have discussed elsewhere the autonomy of public organizations as involving three substantive dimensions - financial, human resources and policy. Thus, an organization may be given the latitude to make its own decisions about personnel and about spending, but the center may retain controls over the policy choices of the organization. The available evidence, albeit generally not expressed in terms of meta-governance is that central governments tend to maintain the financial purse strings and use those to ensure adequate compliance along other dimensions of activity (Wanna, Jensen and De Vries 2004). As well as varying substantively, the maintenance of controls from the center may also be strategic or operational. That is, the control organizations may attempt to either control the frame of action of the (presumably) autonomous organizations, or they may attempt more direct management of the day-to-day decisions made by the organizations. The former may more clearly approximate the logic of "steering at a distance", but both represent some diminution of the real autonomy of the organizations.

The point of this discussion is that autonomy and control may not be as incompatible in practice as they may appear conceptually. The logic of meta-governance, and the "knitting" to which I alluded above, is that both these concepts must co-exist, and are beginning to co-exist more effectively, within contemporary political systems. As argued concerning the utilization of soft law as an instrument for meta-governance, the actual mixture of autonomy and control is likely to be contingent and may also be dependent upon the particular political system. The task for both the academic analyst and the practitioner is to identify mixtures that can at once deliver effective political (democratic) control and maintain the efficiency gains that appear to have resulted from many of the NPM reforms. To square this circle, maintaining one or a few primary controls, usually the budget, may be an effective strategy for meta-governance. 


\section{Performance Management}

Finally, the increasing use of performance management in almost all developed democracies, and many other systems, provides a means of controlling potentially autonomous organizations (see OECD 2007; Peters 2007). Although the term may be used in a variety of ways, the fundamental idea is that by using measurable targets for the results of public programs, central control organizations can monitor and control the behavior of those organizations. This technique therefore shifts the mantra of New Public Management from "Let the managers manage" to "Make the managers manage", meaning that some of the latitude inherent in the management ideas of NPM.

Performance management has some attributes in common with soft law as an instrument for meta-governance. In particular, this method relies on negotiating frameworks and contracts to impose control over the organizations delivering services, as well as the individuals involved in those programs. The targets that are established in performance management tend to be flexible, or tend to be progressive, so that the steering is rather "soft", and permit the organizations involved to have some latitude in how they reach the performance targets. In addition, levels of compliance tend to be progressive so that the levels at which any organization must perform tend to be negotiated year after year, with some continuing ability to affect the outcomes of performance management.

Performance management can help to solve several of the problems created by earlier reforms of the public sector. For example, when performance measurement and management are used internally between ministries and their components (including perhaps contractors as well as formal institutions within the public sector), they are important elements of internal management and steering. However, when applied more directly by external organizations - parliaments, auditors, central agencies - then performance management can be a very useful component for accountability. Especially when the performance standards are made public, these indicators are important for accountability as well as for establishing general democratic frameworks for action.

\section{Conclusion}

Governance has been and continues to be a scarce commodity in most countries. In many ways, the capacity to govern has been enhanced significantly over the past several decades through the spread of the ideas of both New Public Management and the ideas of governance. These approaches to governing both tended to enhance the autonomy of lower-level components of the governing system, whether sub-national governments, agencies or networks linking public and private actors. The capacity of organizations to make more of their own choices, and the capacity 
to employ management techniques not familiar to the public sector, have tended to make government more efficient and effective in service delivery.

Despite the successes of many aspects of reform in the public sector, the problems of accountability and control that were inherent in these reforms have engendered a subsequent round of change. Although it is impossible to return to the governance models that were the object of the NPM and "governance" reforms, some mechanisms for addressing the accountability and other fundamental democratic issues raised by the first round of reforms are required. The perceived negative consequences of reforms have produced some new types of governing, discussed here as "meta-governance".

The primary governance task, as outlined in this paper, therefore is to knit together these two strands of change in the public sector. While the one strand represents the efficiency drives of governing, the other tends to represent better the political, and especially democratic, aspirations for governing. The fundamental point here is that these two can be knit together effectively, but that the knitting will depend upon a number of contingent factors. The first rounds of reform (and especially NPM) tended to assume that one size fit all, but the ability to use management techniques as well as the types of meta-governance that are viable are dependent upon a number of political and policy factors that require additional explication. Thus, the task of coping with governance will continue to require extensive research and analysis by both practitioners and academic analysts.

\section{References}

6, P., D. Leat, K. Setzler and G. Stoker. 2002. Toward Holistic Governance: The New Reform Agenda. Basingstoke: Palgrave.

Adler, E. 1992. "The Emergence of Cooperation: National Epistemic Communities and the International Evolution of the Idea of Nuclear Arms Control." International Organization 46, 105-115.

Bakvis, H. and L. Juillet. 2004. The Horizontal Challenge: Line Departments, Central Agencies and Leadership. Ottawa: Canadian School of Governance.

Bouckaert, G., D. Ormond and B. G. Peters. 2000. A Possible Governance Agenda for Sweden. Helsinki: Ministry of Finance.

Buchanan, J. M. and G. Tullock. 1962. The Calculus of Consent. Ann Arbor: University of Michigan Press.

Caplan, B. 2007. The Myth of the Rational Voter: Why Democracies Choose Bad Policies. Princeton: Princeton University Press.

Christensen, T. and P. Laegreid. 2007. Transcending New Public Management: The Transformation of Public Sector Reforms. Aldershot; Ashgate. 
Christensen, T. and P. Laegreid. 2001. New Public Management: Transformation of Ideas and Practice. Aldershot: Ashgate.

Dente, B., L. Bobbio and A. Spada. 2003. "Government or Governance of Urban Innovation?" DISP 162 (3), 1-22.

DiIulio, J. J. 1994. Deregulating Government. Washington, DC: The Brookings Institution.

Gregory, R. 2004. "All the King's Horses and All the King's Men: Putting the New Zealand Public Sector Together Again., International Public Management Journal vol.4, 41-58.

Heffernan, R. 2003. "Prime Ministerial Predominance?: Core Executive Politics in the United Kingdom." British Journal of Politics and International Relations 5, 347-372.

Helmke, G. and S. Levitsky. 2004. "Informal Institutions and Comparative Politics: A Research Agenda." Perspectives on Politics 2, 725-740.

Hood, C. 1991. “A Public Management for All Seasons?” Public Administration 69, 3-19.

Huber, J. D. and C. R. Shipan. 2002. Deliberate Discretion. Cambridge: Cambridge University Press.

Jensen, L. 2004. Den store koordinator. Kobenhavn: Jurist og Økonomi.

Klijn, E.-H. and J. Koopenhaan. 2005. Managing Uncertainties in Networks. London: Routledge.

Marinetto, M. 2003. "Governing Beyond the Centre: A Critique of the Anglo-Governance School." Political Studies 51, 592-608.

Meyers, M. K. and S. Vorsanger. 2004. "Street-Level Bureaucrats and the Implementation of Public Policy." In B. G. Peters and J. Pierre (eds). The Handbook of Public Administration. London: Sage, pages.

Morth, U. 2003. Soft Law in Governance and Regulation: An Interdisciplinary Analysis. Cheltenham: Edward Elgar.

Mulgan, G. 2000. "Accountability: An Ever-Expanding Concept." Public Administration 78, 555-573.

Niskanen, W. 1971. Representative Government and Bureaucracy. Chicago: Aldine/Atherton.

OECD. 2007. Performance Management in the OECD Countries. Paris: Organization for Economic Cooperation and Development.

O’Toole, L. J. 2007. "Governing Outputs and Outcomes of Governance Networks." In E. Sorenson and J. Torfing (eds). Theories of Democratic Network Governance. Basingstoke: Palgrave, pages. 
Olsen, J. P. forthcoming. “The Ups and Downs of Bureaucratic Organization.” Annual Review of Political Science 11, 13-37.

Osborne, D. and T. Gaebler. 1991. Reinventing Government. Reading, MA: AddisonWesley.

Peters, B. G. 2007a. "Performance Management in the Nordic Countries". Paper Prepared for Annual RAKO Conference, Lidingö, Sweden, 11 September.

Peters, B. G. 2007b. "Central Agencies and Executive Governance." Paper presented at Joint Workshops of the European Consortium for Political Research, 5-10 May.

Peters, B. G. 2004. "Back to the Centre?: Rebuilding the State." The Political Quarterly, Special issue on "Restating the State", 130-140.

Peters, B. G. 2005. "Governance and Public Bureaucracy: New Forms of Democracy or New Forms of Control?” Asia-Pacific Journal of Public Administration 26, 3-16.

Peters, B. G. 2001. The Future of Governing. $2^{\text {nd }}$ edn. Lawrence: University Press of Kansas.

Peters, B. G. and J. Pierre. 2004. Politicization of the Public Service: The Quest for Control. London: Routledge.

Pierre, J. 2000. Governance, Politics and the State. Basingstoke: Palgrave.

Pollack, J. K. 1951. “The Primacy of Politics.” American Political Science Review 45, $1-17$.

Pollitt, C. 2003. "Joined Up Government: A Survey." Political Studies Review 1, 3449.

Pollitt, C. and C. Talbot. 2004. Unbundled Government: A Critical Analysis of the Global Trends to Agencies, Quangos and Contractualisaton. London: Routledge.

Rokkan, S. 1967. “Norway: Corporate Pluralism.” In R. A. Dahl (ed.). Political Oppositions in Western Democracies. New Haven: Yale University Press, 70-115.

Rose, R. 1974. The Problem of Party Government. London: Macmillan.

Salamon, L. M. 2001. "Introduction." In Salamon (ed.). The Handbook of Policy Instruments. New York: Oxford University Press, 3-31.

Savoie, D. J. 2004. Governing from the Centre. Toronto: University of Toronto Press. Scharpf, F. W. 1988. "The Joint-Decision Trap: Lessons from German Federalism and European Integration." Public Administration 66, 239-278.

Schofield, J. 2001. "The Old Ways are the Best?: The Durability and Usefulness of Bureaucracy in Public Sector Management." Organization 8, 77-96.

Sørenson, E. and J. Torfing. 2006. Theories of Democratic Network Governance. London: Palgrave. 
Verhoest, K., P. Humphreys and K. Rubecksen. forthcoming. The Autonomy of Public Agencies: A Comparative Analysis. Basingstoke: Palgrave.

Von Mettenheim, K. 1997. Presidential Institutions and Democratic Politics: Comparing Regional and National Contexts. Baltimore, MD: Johns Hopkins University Press.

Walsh, H. and J. Stewart. 1992. "Change in the Management of the Public Service." Public Administration 70, 499-518.

Wanna, J., L. Jensen and J. De Vries. 2003. Controlling Public Expenditure: The Changing Role of Central Budget Agencies-Better Guardians? Cheltenham: Edward Elgar.

Whitford, A. B. 2002. "Decentralization and Political Control in Bureaucracy." Journal of Theoretical Politics 14, 167-193.

Yesilkagit. K. 2007. "Whose Regulators?: Competing Perspectives on Bureaucratic Autonomy." Paper presented at Biannual Meeting of the European Consortium for Political Research, Pisa, Italy, 6-8 September. 